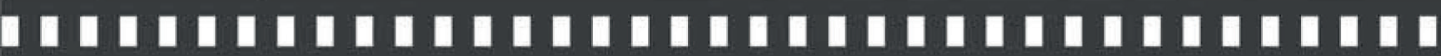

\author{
Roma é a mãe! Fotojornalismo e \\ uma análise do clube-empresa \\ Roma Esporte Apucarana
}

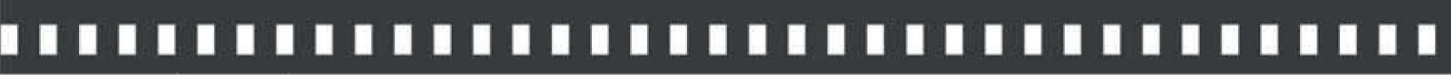

Heron Heloy Costa

Paulo César Boni

Artigo recebido em: 15/06/2016

Artigo aprovado em: 07/10/2016 


\title{
Roma é a mãe! Fotojornalismo e uma análise do clube-empresa Roma Esporte Apucarana
}

\author{
Roma is the mother! Photojournalism and an analysis about \\ a corporate soccer club called Roma Esporte Apucarana
}

Heron Heloy Costa* e Paulo César Boni***

\begin{abstract}
Resumo: Este trabalho é um estudo sobre a intencionalidade de comunicação no fotojornalismo (BONI, 2000), traçando características do clube-empresa no futebol brasileiro a partir do Roma Esporte Apucarana, extinto time de futebol de Apucarana - região norte do Paraná. As fotorreportagens analisadas são do jornal apucaranense Tribuna do Norte, publicadas em um contexto que compreende os anos de 2001 a 2007.
\end{abstract}

Palavras-chave: Roma Esporte Apucarana. Clube-empresa. Intencionalidade de comunicação no fotojornalismo. Tribuna do Norte.

\begin{abstract}
This is a study about communication's intentionality on the photojournalism (BONI, 2000). The article underlines characteristics of corporate soccer club in Brazilian soccer. The starting point for that is Roma Esporte Apucarana, an extinct Apucarana's (North of Paraná State, Brazil) soccer team. The photo reports analyzed were published in a newspaper from Apucarana called Tribuna do Norte - between 2001 and 2007.
\end{abstract}

Keywords: Roma Esporte Apucarana. Corporate soccer club. Communication intentionality on photojournalism. Tribuna do Norte.

* Graduado em Comunicação Social/Jornalismo pela Universidade Estadual de Londrina e Mestrando em Comunicação também pela Universidade Estadual de Londrina. Pesquisa na área de Comunicação e Futebol.

** Graduado em Comunicação Social - Habilitação Jornalismo pela Universidade Estadual de Londrina (1981). Mestre em Comunicação Social pelo Instituto Metodista de Ensino Superior de São Bernardo do Campo (1992). Doutor em Ciências da Comunicação pela Universidade de São Paulo (2000). Professor da Universidade Estadual de Londrina, desde 1982, sendo professor associado desde 2006. 


\section{Introdução}

Entender o futebol é entender o Brasil. No Paraná, temos provas disso: enquanto capital e região metropolitana torcem por um dos três do "Trio de Ferro", Atlético, Coritiba e Paraná Clube, o norte do estado divide suas atenções entre times paulistas e até mesmo cariocas. Os exemplos refletem os costumes e as formas como foi colonizado o estado.

Roberto DaMatta em Universo do futebol: esporte e sociedade brasileira, livro de 1982, tido como pontapé inicial para os estudos acadêmicos sobre futebol no país, afirma que fica mais fácil interpretar a sociedade brasileira a partir do momento em que se compreende sociologicamente o futebol aqui disputado.

Tendo como ponto de partida o fotojornalismo do jornal Tribuna do Norte, de Apucarana-PR, abordamos a história do Roma Esporte Apucarana e, a partir dela, traçamos características do chamado "clube-empresa", fenômeno recente do futebol brasileiro que tem por objetivo gerir clubes de futebol ao molde de empresas. Também a partir das fotografias, abordamos a intencionalidade de comunicação no fotojornalismo (BONI, 2000). Segundo esta proposta metodológica de análise, a forma como o fotógrafo compõe a mensagem fotográfica (angulação, planos de tomada, focagem e desfocagem, entre outros) pode indicar sua intenção de informar, assim como o repórter de texto o faz com palavras. Além da intenção do repórter-fotográfico, a pauta e a edição são processos que também podem influenciar no resultado final da produção.

A metodologia do trabalho consistiu em um levantamento de 3.638 edições do jornal, entre os anos de 2000 e 2012, além da pesquisa de referenciais teóricos acerca do tema. Quanto ao processo de produção, foram feitas entrevistas com dois dos fotojornalistas estudados: Jair Ferreira e Sérgio Rodrigo, e também com o repórter e editor de esportes do jornal, Raul César dos Reis.

No entanto, para este artigo, apresentamos um recorte de fotografias publicadas entre 2001 e 2007 . O período representa 
a fase na qual o time de Apucarana foi gerido por João Wilson Antonini (Kiko), fundador e dono do time. Assim, as quatro fotografias analisadas representam pontos de destaque da história do clube.

Antes de darmos - de fato - o pontapé inicial, cabe uma explicação sobre o título deste artigo: Roma é a mãe! O nome do extinto clube-empresa de Apucarana ${ }^{1}$ é uma homenagem do fundador Kiko a sua mãe, dona Romilda. Como Romilda Esporte Apucarana não cairia bem para o nome de um time, Kiko abreviou para Roma e assim ficou.

\section{Clube-empresa: um breve histórico até o Roma}

\section{Apuracana}

Final do campeonato paulista 2016. De um lado o Santos, time centenário pelo qual já passaram Pelé, Zito, Pepe e outros grandes nomes do futebol brasileiro e internacional. Do outro, o Audax, time com pouco mais de três décadas de existência e que mudou de cidade após a venda para o Grêmio Osasco em 2013. A chegada do Audax à decisão reacendeu a discussão sobre o modelo de clube-empresa na gestão dos times brasileiros. Prós à ideia citam a organização fora de campo e as estratégias de marketing que profissionalizam os clubes. Já os contrários ao molde clube-empresa citam justamente o caráter "cigano" destas instituições, que podem mudar de cidade/sede a qualquer mudança de temporada.

Um dos pontos a serem destacados quando se trata da mudança de pensamento da gestão no futebol brasileiro é a Lei $\mathrm{N}^{\circ}$ 9.615/98, mais conhecida como Lei Pelé. É o que defende Rafael do Nascimento Grohmann no artigo Comunicação, futebol e sociologia: confluências possíveis, presente no livro Comunicação e esporte: reflexões.

1 O time se fundiu em 2014 com o Cincão Esporte Clube e adotou o nome de Apucarana Sports. 
A implantação da Lei Pelé (Lei No 9.615/98) é, portanto, importante paraacompreensão dos fenômenosenvolvendo o futebol brasileiro atual e as dinâmicas que se dão entre clube ejogador de futebol(GROHMANN, 2012, p. 80-81).

Duas das principais mudanças obtidas com a Lei Pelé foram: o fim do direito que os times de futebol tinham sobre o passe do jogador ${ }^{2}$ e a obrigatoriedade, a partir da data em que a lei foi sancionada, de os clubes se tornarem empresas comerciais. É importante o lembrete de que a Lei Pelé não foi a primeira tentativa de se fazer uma legislação dos esportes mais aberta aos interesses do mercado da bola. Em 1993, a Lei Zico (Lei No 8.672/93) já propunha o fim do passe e a obrigatoriedade dos clubes serem geridos como empresas.

A década de 90 foi marcada pela busca da supremacia de mercado entre setores que comandavam a vida esportiva do futebol brasileiro; essa situação ficou muito bem demonstrada na elaboração da legislação esportiva de 1993 (Lei Zico) e de 1998 (Lei Pelé). Essas mudanças visavam retirar os empecilhos, forjados anteriormente pelo Estado, para a integração do futebol aos interesses do mercado, situados principalmente no capital financeiro nacional e internacional (OURIQUES, 1999, p. 43).

Mesmo antes de a Lei Pelé ser oficializada, o futebol brasileiro já vivia um momento de globalização, após seus três títulos de Copa do Mundo (1958, 1962, 1970). Se nas disputas de 1970, 1974 e 1978 todos os jogadores convocados atuavam no Brasil, para o Mundial de 1982, na Espanha, apareceram os nomes de Falcão e Dirceu, que jogavam, respectivamente, pelo

2 Direitos econômicos ligados à venda de um jogador de futebol para outro time. 
Roma (Itália) e pelo Atlético de Madrid (Espanha). De lá para cá, a gangorra pendeu cada vez mais para os clubes internacionais nas convocações da seleção de futebol da Confederação Brasileira de Futebol (CBF).

De fato, diferentes análises sociológicas do futebol brasileiro apontam o período após a Copa de 1950 como o começo da internacionalização. No artigo $\mathrm{O}$ gol contra do rei: a Lei Pelé e suas conseqüências, Nilso Ouriques cita o artigo Esporte e sociedade: o caso do futebol brasileiro, no qual Robert M. Levine (1982) sublinha quatro fases do esporte em questão: 1894-1904, com o futebol restrito aos clubes urbanos pertencentes aos estrangeiros; 19051933, a fase amadora, marcada pela grande divulgação e pressão constantes para melhorar o nível do jogo por meio de subsídios para os jogadores; 1933-1950, início do profissionalismo; e pós-1950, o reconhecimento internacional acompanhado da comercialização dos jogadores.

Já João Máximo (2006) em Brasil: um século de futebol arte e magia divide de outra forma, mas com semelhanças: 1894-1930 como o "fim da infância" do jogo; 1930-1956, os anos românticos do futebol; 1956-1970, a "Taça do Mundo é nossa", tratando especialmente dos campeonatos conquistados; e, por fim, de 1970 até hoje como o período de "globalização da bola".

Bola e mercado, cada vez mais, tornam-se próximos. Com a obrigatoriedade do clube-empresa decretada, algumas mudanças são notadas, entre elas, o surgimento de times que migram de cidade, caso do Roma de Barueri que, em dezembro de 2000, virou Roma Esporte Apucarana, após parceria entre a prefeitura local e o empresário João Wilson Antonini, dono do time (à época em Barueri-SP). Ou seja, o Roma de Apucarana nasceu a partir de uma canetada em um escritório, uma origem pitoresca para um time de futebol, sem dúvidas. Na assinatura do contrato, uma fala do presidente Kiko destaca o modelo de clube-empresa:

Kiko disse que o Roma de Apucarana é um clube- 
empresa e está dentro da Lei Pelé. Tem como objetivo participar de campeonatos a nível estadual, nacional e até internacional, e também comprar e vender jogadores. 'Viemos para Apucarana como empresa', ressaltou. (TRIBUNA DO NORTE, 14 jan. 2001).

\section{Tribuna do Norte: história e processo produtivo}

A Tribuna do Norte (TN) é um jornal impresso de circulação praticamente diária (não tem edição às segundas-feiras, exceto em dias pós-eleição), com sede em Apucarana-PR, à Rua Desembargador Clotário Portugal, 1.420. O veículo cobre pautas relacionadas principalmente à região do Vale do Ivaí ${ }^{3}$ A TN circula em Apucarana, Arapongas, Londrina e Curitiba, além dos municípios do Vale do Ivaí (ao todo, circula em 40 cidades), com tiragem de 10.000 exemplares/dia.

O periódico surgiu, em formato tabloide, no dia 3 de março de 1991, a partir da fusão de outros dois jornais do município: Tribuna da Cidade (1971-1991) e Jornal do Norte (1985-1991). Após 1994, a TN passou por reformulações em sua logomarca e também no conteúdo do jornal, porém, não mais modificou seu formato (já standard). Atualmente trabalha com uma roupagem mais visual, com uso de infográficos e charges em suas páginas. De acordo com Raul César dos Reis, repórter de esportes do jornal desde 1991 e também atual editor da editoria esportiva, há um aconselhamento para que os repórteres produzam textos mais curtos e deem mais destaque a fotografias e a infográficos. Os textos dificilmente excedem os 2.000 caracteres por matéria. Em caso de conteúdo mais aprofundado, utilizam-se boxes explicativos.

Em relação à editoria analisada neste trabalho - Esportes 3 Região situada no norte do estado do Paraná, composta por 28 municípios, sendo que o maior deles é Apucarana. Cidades menores como Borrazópolis, Faxinal e Ivaiporã compõem a região que, com cerca de 309 mil habitantes (IBGE, 2007) representa 3\% da população paranaense. 
- Raul explicou em entrevista ao autor que o foco são os times principais do estado de São Paulo: Corinthians, Palmeiras, Santos, São Paulo e, às vezes, o Flamengo, por conta de ser um clube com torcedores em todo o país, inclusive, na região do Vale do Ivaí. Isso, evidentemente, quando não há nenhum time da região disputando competições ou amistosos. O esporte amador também ganha destaque, principalmente quando há apucaranenses na disputa ou quando os torneios são disputados na cidade.

O fotojornalista Sérgio Rodrigo também foi entrevistado. Ele relata que nem sempre é possível acompanhar todo o jogo, no caso do futebol, por conta justamente de ter de cobrir várias pautas por dia. Aos domingos a possibilidade de fotografar durante toda a partida é concreta, por conta de o jornal não circular às segundas-feiras, ou seja, dificilmente haverá outras pautas no domingo. A TN também não costuma mandar seus fotojornalistas para coberturas fora da cidade, a não ser em casos de disputas em cidades próximas, como Arapongas ou Londrina. O que também pode ser feito, dependendo da demanda por fotografias na redação, é um fotojornalista ser deslocado para um jogo que não seja do Roma, para fazer imagens de arquivo dos times da capital (Atlético Paranaense, Coritiba e Paraná). Essas imagens são usadas ao longo do ano nas notícias do Campeonato Brasileiro ou de outras competições que envolvam o trio de ferro da capital.

O relato dos fotojornalistas e do editor Raul César dos Reis se justifica, pois entender a dinâmica de produção do jornal ajuda a embasar a análise.

Contudo, mais que a supressão da carência bibliográfica, a opção pela entrevista representa o nosso pensar que as pessoas mais indicadas para falar sobre fotojornalismo são os profissionais da área, ou seja, os repórteres fotográficos (BONI, 2000, p. 228).

Outra estratégia adotada é a troca de fotografias entre 
jornais, em especial quando se trata de uma competição esportiva disputada em dois turnos. Por exemplo, se o Apucarana Sports ${ }^{4}$ vai jogar fora de casa contra o Atlético Clube Paranavaí (ACP) pelo primeiro turno do campeonato paranaense, a TN usa uma foto do Diário do Noroeste, de Paranavaí. No segundo turno, quando o ACP vier a Apucarana jogar, fotografias feitas pelos repórteres da TN são enviadas para o jornal de lá. As fotografias que o jornal utiliza para assuntos não-regionais são retiradas de internet ou de agências como: Agência Brasil, Agência Estadual de Notícias e Vipcomm.

\section{Fotojornalismo e Roma Apucarana: o clube-}

\section{empresa nas páginas da Tribuna do Norte}

O objetivo desta análise não é adivinhar e transcrever exatamente o que os fotojornalistas quiseram comunicar em suas fotografias, mas, sim, aproximar significações dentro de determinados contextos, tendo em mente as possibilidades de intencionalidade de comunicação nas pautas. Conforme observa Joly (1996, p. 44):

Ninguém tem a menor idéia do que o autor quis dizer; o próprio autor não domina toda a significação da imagem que produz. [...] Interpretar uma mensagem, analisá-la, não consiste certamente em tentar encontrar ao máximo uma mensagem preexistente, mas em compreender o que essa mensagem, nessas circunstâncias, provoca de significações aqui e agora, ao mesmo tempo que se tenta separar o que é pessoal do que é coletivo.

A primeira fotografia analisada (Figura 1) é a única, das constantes neste estudo, que não contém presença humana. Trata-

$4 \quad$ Atual time de futebol da cidade de Apucarana-PR. 
se de uma imagem tomada por Jair Ferreira e publicada no dia 9 de janeiro de 2001, ocupando as seis colunas de largura no jornal.

Figura 1: "Começam as reformas no Estádio Bom Jesus da Lapa"

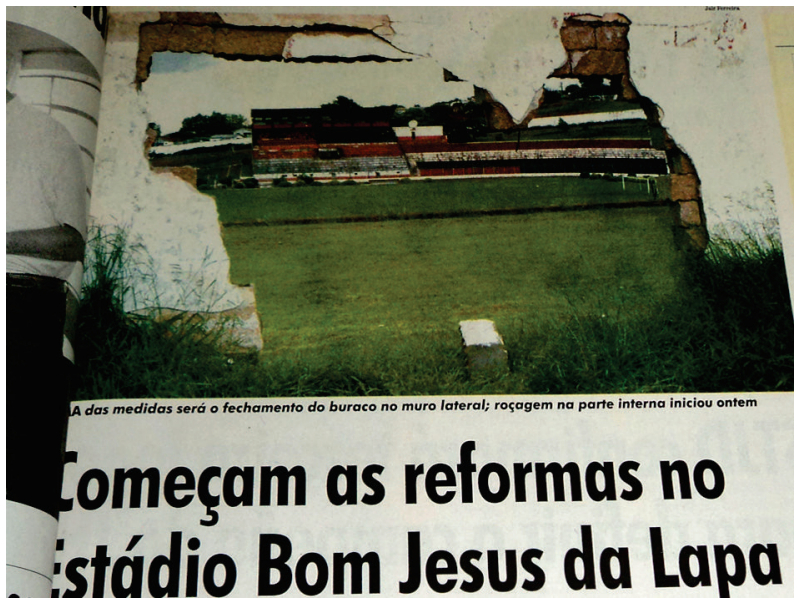

Fotografia: Jair Ferreira

Fonte: Arquivo da Tribuna do Norte (9 de janeiro de 2001)

Em primeiro plano, vemos um muro quebrado. Pelo mato que cresce ao lado do buraco, podemos concluir que se trata de um lugar abandonado ou que há algum tempo não recebe reformas. $\mathrm{O}$ mesmo muro quebrado serve, na fotografia, de moldura à arquibancada coberta e parte do anel geral do estádio Bom Jesus da Lapa que, pelas cores desbotadas e tinta descascando, também indicia sinais de abandono.

Apesar de não conter o elemento humano, nesse caso a fotografia diz mais apenas com a paisagem. A pauta poderia ter sido direcionada de forma a ilustrar a situação, por exemplo, com uma imagem "boneco" do prefeito, explicando que a prefeitura iria retomar as obras no estádio municipal. No entanto, a fotografia do estádio, com seu muro quebrado e suas arquibancadas desbotadas, remete à ideia de que essa praça esportiva de Apucarana está 
abandonada desde que o último clube da cidade parou de disputar competições oficiais de futebol.

A manchete da matéria "Começam as reformas no Estádio Bom Jesus da Lapa" alenta o torcedor apucaranense. Tem-se a ideia de que, com a chegada do Roma, haverá um novo início para o futebol do município. A linha fina da matéria é: "Estrutura deverá estar pronta até dia 20 deste mês, quando a equipe do Roma chega à cidade". Ou seja, ao ver a fotografia e ler o respectivo texto, o pensamento é de que o Roma será o responsável por reviver o futebol na cidade.

O Roma completou seu primeiro aniversário em Apucarana no dia 6 de dezembro de 2001. No dia posterior, a matéria "Roma completa um ano em Apucarana" (Figura 2) comenta o fato, com uma imagem que ocupa quatro colunas de largura.

Figura 2: "Roma completa um ano em Apucarana"

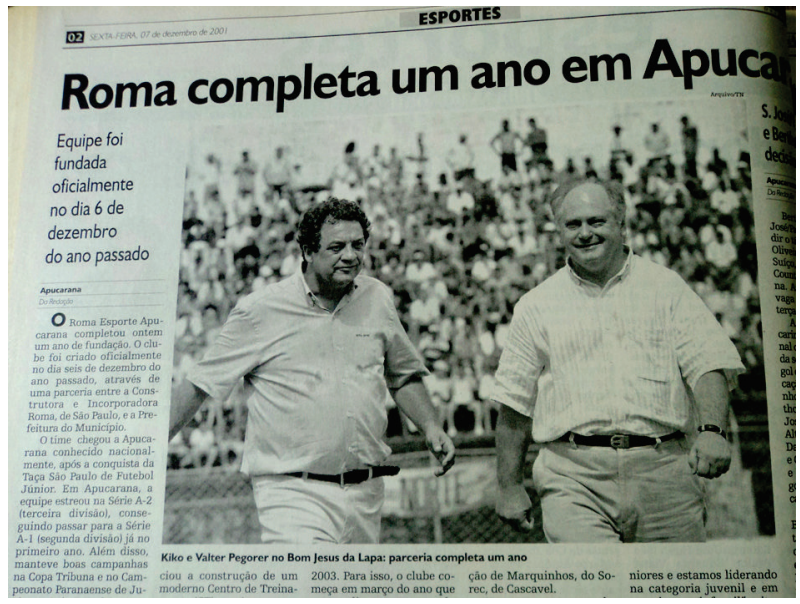

Fotografia: Crédito não informado pelo jornal

Fonte: Arquivo da Tribuna do Norte (7 de dezembro de 2001)

A fotografia que acompanha o texto é uma imagem do arquivo da TN, de Kiko e do prefeito de Apucarana na gestão 2001- 
2004, Valter Aparecido Pegorer (à época, PFL). Ambos ocupam o primeiro plano da captura e estão enquadrados do joelho para cima, o que caracteriza o plano americano. No sentido de visão do leitor, Kiko está à esquerda e Pegorer à direita, com a torcida apucaranense desfocada em segundo plano. A impressão que se tem é de estádio lotado porque, da posição na qual o fotógrafo fez o registro, é possível visualizar exatamente o setor da arquibancada geral onde as torcidas organizadas costumam ficar durante as partidas. Na própria imagem, é possível reparar uma das faixas da torcida organizada "Dragões do Norte", entre os braços de Kiko e do prefeito. Por sinal, o enquadramento de apenas parte da faixa, com a palavra "Norte", carrega de significados a imagem.

A intencionalidade de comunicação do repórter fotográfico ao documentar alguma ocorrência para o veículo em que trabalha é manifesta pela forma como compõe a mensagem fotográfica. Ele se sente tão responsável pela informação quanto o repórter de texto. Sente a necessidade de traduzir para o leitor, através de imagens, o que testemunhara por estar presente ao local do ocorrido. A intencionalidade se evidencia em razão de ele primeiro construir seu significado pessoal do fato e depois, utilizando-se dos recursos técnicos e dos elementos da linguagem fotográfica, tentar traduzi-lo para o leitor (BONI, 2000, p. 200).

Segundo as definições de Ferreira (2008, p. 580), norte pode ter como significado "rumo, direção". Ao observar a figura 2, percebe-se que Kiko e Pegorer caminham e olham para direções diferentes. Enquanto o prefeito de Apucarana tem um sorriso calmo e de satisfação, Kiko está mais sisudo. Pegorer olha para algum ponto levemente à esquerda de onde estava o fotógrafo da $\mathrm{TN}$, já Kiko desvia sua atenção para um ponto à direita do posto que ocupava o fotógrafo. Outra diferença que se nota é em relação ao caminhar dos dois: Pegorer tem passos mais lentos e compassados, 
e Kiko parece andar de forma mais apressada. Dois aspectos da fotografia nos permitem concluir isso: o corte de parte do braço do presidente do Roma e a forma como sua camisa está franzida próxima ao mesmo braço cortado na imagem, o que indica um movimento mais rápido na fração de segundo da captura. Na camisa de Pegorer, por exemplo, não notamos sinais de movimento brusco.

Trata-se de uma imagem de arquivo que, provavelmente, foi feita no dia de algum pronunciamento oficial da diretoria do Roma e da prefeitura de Apucarana aos torcedores. É possível assim concluir, pois essa seria uma das poucas oportunidades na qual prefeito e presidente do clube estariam reunidos no gramado do estádio. O fotojornalista congelou o instante no qual Kiko e Pegorer chegavam ou saíam para discursar à torcida. Considerandose a posição e profundidade da dupla em relação aos torcedores, pode-se afirmar que se encontravam no meio do campo do Bom Jesus - fotografados por uma lente teleobjetiva - e que a captura foi feita em ângulo contre-plongée ${ }^{5}$, o que valoriza as figuras de Kiko e Pegorer, além da impressão da imagem em preto e branco, que contribui para que o foco de leitura seja em cima dos dois e transforma os torcedores ao fundo em pontos.

A editoria de esportes da $\mathrm{TN}$, no geral, tem entre uma e quatro páginas, mas a parte local, ao longo dos 12 anos pesquisados, se manteve com uma ou, no máximo, duas páginas. O Roma ocupou as quatro páginas apenas quando foi campeão da Copa 100 Anos da Federação Paranaense de Futebol ${ }^{6}$, em 2006. Na ocasião (28 de novembro de 2006), também foi o recorde de fotografias $(10+2$ pôsteres) nas reportagens. Ou seja, em termos quantitativos, essa

5 Do francês plongée, mergulho. Ângulo de enquadramento no qual a câmera está posicionada abaixo do nível dos olhos do fotografado, voltada para cima.

6 Em 2006, como forma de manter os times do interior com calendário de jogos para o segundo semestre, a Federação Paranaense de Futebol (FPF) criou a Copa 100 Anos. Disputaram o torneio clubes como Londrina, Iraty, o próprio Roma e equipes juniores dos três da capital (Atlético Paranaense, Coritiba e Paraná). 
foi a edição da TN (Figura 3) que deu mais destaque ao Roma.

Figura 3: Capa: "ROMA É CAMPEÃO!"

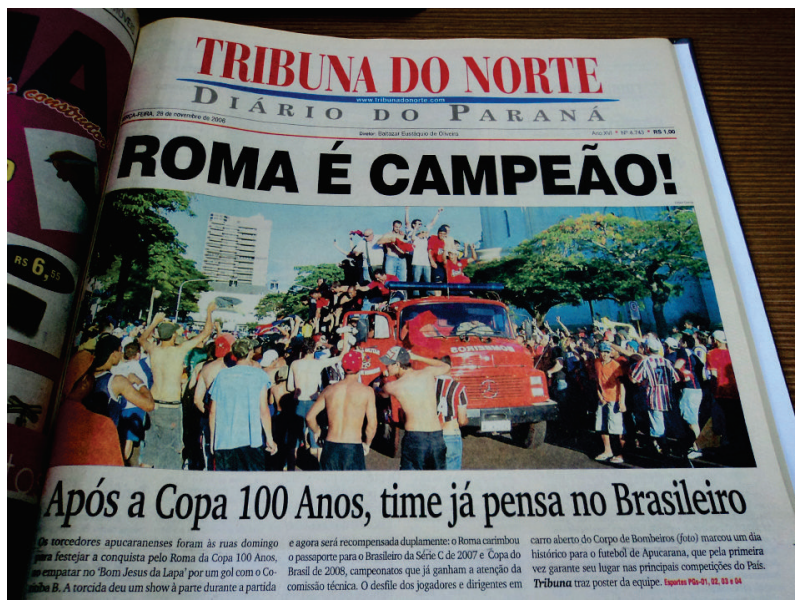

Fotografia: Delair Garcia

Fonte: Arquivo da Tribuna do Norte (28 de novembro de 2006)

A fotografia foi feita na Avenida Curitiba, uma das principais da cidade, ao lado da catedral. Na imagem, a cena típica de quando um time ganha uma competição: o desfile em carro de bombeiros pelas principais avenidas do município, o encontro entre jogadores e torcedores, a saudação dos munícipes e outros elementos festivos. Fato interessante de se observar é que nenhuma das pessoas retratadas no ângulo de tomada da imagem usa camiseta ou qualquer acessório do Roma. Por sinal, na imagem só é possível visualizar duas camisetas de times de futebol e ambas são do uniforme reserva do São Paulo (tricolor em preto, branco e vermelho).

Chama a atenção, na capa, duas formas não-utilizadas pelo projeto editorial da TN e na maioria dos jornais de circulação diária: a manchete escrita com todas as letras em caixa alta e com o uso de exclamação ao fim da mesma (ROMA É CAMPEÃO!). Com a conquista da Copa 100 Anos, o Roma ganhou vaga para disputar a 
série C nacional de 2007 e a Copa do Brasil de 2008.

Por último, temos uma fotografia publicada no dia 16 de março de 2007. À época, o Roma se preparava para a disputa da Série $\mathrm{C}$ do campeonato nacional, feito inédito para uma equipe da Cidade Alta". Sob a manchete "Roma pode fechar parceria", o texto relata uma possível mudança para Londrina, no ano de disputa da terceirona do Brasileirão. O chapéu da reportagem é taxativo: "A agremiação de Apucarana deverá se fundir hoje com o Londrina Esporte Clube".

A matéria da TN estampa duas fotografias. Uma, no conteúdo principal, de Kiko em posição de defesa de argumentos, provavelmente em meio a alguma entrevista já dada ao jornal. Pode-se concluir isso, pois o crédito da fotografia era "Arquivo/ TN". A segunda fotografia da página (figura 4) ocupa três colunas e não contém crédito. É ela que analisaremos.

Das possibilidades de torcedor do Roma ou de apucaranense existentes, a pauta foi direcionada para se entrevistar Jorge Maia Filho, ex-deputado estadual e que, no dia anterior ao da veiculação do material, havia se desligado da comissão criada para viabilizar a iluminação do Estádio Bom Jesus da Lapa. Acima da legenda, “O torcedor Jorge Maia Filho está revoltado com a possível fusão entre Roma e Londrina", podemos observar um cenário que se assemelha ao de um escritório. Na prateleira atrás de Maia Filho, é possível ver livros, enciclopédias, uma caixa e um quadro. A mesa na qual o entrevistado está sentado completa a ideia de um ambiente de trabalho. Essa é a imagem que o leitor possivelmente tem a partir da leitura fotográfica, porém, o cenário nada mais é do que o arquivo do jornal TN, onde ele foi entrevistado. Joly (1996, p. 43) assinala que "de fato, mesmo nas mensagens visuais que nos parecem mais 'realistas', existem muitas diferenças entre a imagem e a realidade que ela supostamente deveria representar".

$7 \quad$ Alcunha de Apucarana, devido à elevada altitude da cidade (850 metros acima do nível do mar). 
Figura 4: "Kiko está traindo a torcida, diz Maia"

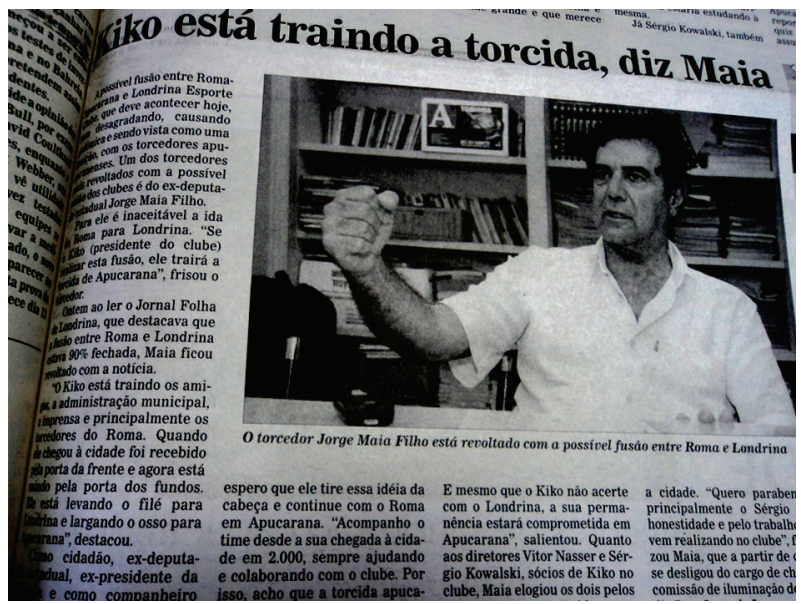

Fotografia: Crédito não informado pelo jornal

Fonte: Arquivo da Tribuna do Norte (16 de março de 2007)

O cenário e o fato de Maia Filho ser ex-deputado estadual compõem a figura de um torcedor consciente, que sabe o que afirma. Não se trata de alguém fotografado em uma arquibancada, comendo amendoins durante um jogo e opinando no calor da partida; mas sim, de uma pessoa que já representou Apucarana na esfera estadual. Outro aspecto interessante da captura é notar que, embora a legenda e o próprio texto afirmem se tratar de um torcedor, o ex-deputado não usa camiseta, boné ou qualquer outro acessório que o identifique como um fã do Roma. Se a fotografia fosse utilizada em outra editoria, poderíamos acreditar se tratar de um economista, sociólogo ou professor. Essa representação reflete a falta de identidade do time com os moradores da cidade. Não há uma figura clara de torcedor do Roma.

Sobre a composição da fotografia em si, o que mais detém o olhar é a posição da mão direita do fotografado. Enquadrada em um dos pontos ouro da imagem, a mão cerrada e levantada, como a antecipar um veredito, serve para demonstrar o sentimento de raiva 
e de revolta do torcedor apucaranense em relação à atitude de Kiko, de levar o time para Londrina justamente quando haveria a disputa da Série C nacional.

O olhar de Maia Filho é para o repórter que o entrevista. Essa, aliás, é uma das características do fotojornalismo da TN. Em depoimento ao autor, os dois fotojornalistas afirmaram que não são usuais as fotografias posadas e que o costumeiro é que elas sejam tomadas enquanto o repórter de texto conversa com o entrevistado.

$\mathrm{O}$ enquadramento é feito em plano médio e em leve ângulo contre-plongée, o que, somado ao cenário de fundo com os livros e enciclopédias, valoriza a figura do entrevistado e, consequentemente, suas opiniões.

\section{Considerações finais}

A partir do fotojornalismo do jornal apucaranense Tribuna do Norte vemos contada a história do Roma Esporte Apucarana. Uma história que se inicia com a assinatura de um contrato entre uma prefeitura e uma construtora e que traz consigo o modelo de clube-empresa, atualmente tão comentado no noticiário esportivo. Um modelo que prioriza a gestão e o resultado, mas que não necessariamente cria identificação com o torcedor da cidade onde se "instala" o clube, o que é interessante se pensarmos em um esporte no qual a torcida é parte fundamental da história e da trajetória de um clube.

As imagens apresentadas representammomentosimportantes da história do Roma entre 2000 e 2007, período no qual a equipe foi gerenciada por João Wilson Antonini, dono do time. A forma de análise das fotografias é inspirada na proposta metodológica de Paulo César Boni (2000), que versa sobre a intencionalidade de comunicação no fotojornalismo. Outro referencial teórico trabalhado é Martine Joly, em Introdução à análise da imagem.

Ainda sobre a análise imagética, temos que pontuar a importância das entrevistas como metodologia. Tal qual um treinador 
que já jogou bola é importante para orientar seus comandados, saber como é a rotina de produção e quem são os responsáveis pelo objeto de estudo tornou mais fácil e mais concreta a análise. As três entrevistas feitas foram a oportunidade de comprovar (ou não) hipóteses levantadas.

$\mathrm{O}$ artigo trata de um tema regionalista, por acreditar na importância de se conhecer, em primeiro lugar, nossa própria história. No entanto, o tema não se encerra apenas no Roma de Apucarana, ele está vivo em cada clube-empresa que existe no país (caso do próprio Audax Osasco aqui citado), em cada pesquisa sobre futebol e também em cada análise que atribui ao fotojornalismo uma intencionalidade em sua comunicação.

\section{Referências}

BONI, Paulo César. O discurso fotográfico: a intencionalidade de comunicação no fotojornalismo. São Paulo, 2000. Tese (Doutorado em Ciências da Comunicação) - Universidade de São Paulo, São Paulo, 2000.

DAMATTA, Roberto et al. Universo do futebol: esporte e sociedade brasileira. São Paulo: Edições Pinakhoteke, 1982.

FERREIRA,Aurélio Buarque de Holanda. Miniaurélio: o minidicionário da língua portuguesa. 7. ed. Curitiba: Positivo, 2008.

FERREIRA, Jair. Entrevista concedida a Heron Heloy Costa em 10 de julho de 2013.

GROHMANN, Rafael do Nascimento. Comunicação, futebol e sociologia: confluências possíveis. In: GURGEL, Anderson et al. Comunicação e esporte: reflexões. São Paulo: Intercom, 2012.

IBGE. Dados sobre o Vale do Ivaí, 2007. Disponível em: <http://www. fecea.br/valedoivai/>. Acesso em: 17 jul. 2013. 
JOLY, Martine. Introdução à análise da imagem. Campinas: Papirus, 1996.

LEI Pelé. Lei número 9.615/1998. Diário Oficial da União - Seção 1

- 25/3/1998, Página 1. Disponível em: <http://www.planalto.gov.br/ ccivil_03/leis/19615consol.htm>. Acesso em: 18 maio 2013.

LEI Zico. Lei número 8.672/1993. Diário Oficial da União - Seção 1 - 7/7/1993, Página 9.379. Disponível em: <http://www2.camara.leg. br/legin/fed/lei/1993/lei-8672-6-julho-1993-349784-norma-pl.html>. Acesso em: 18 maio 2013.

LEVINE, Robert. Esporte e sociedade: o caso do futebol brasileiro. In: MEIHY, José Carlos Sebe Bom; WITTER, José Sebastião. (Orgs.). Futebol e cultura: coletânea de estudos. São Paulo: Convênio Imesp/ Daesp, 1982.

MÁXIMO, João. Brasil: um século de futebol arte e magia. São Paulo: Aprazível Edições, 2006.

OURIQUES, Nilso. O gol contra do rei: a Lei Pelé e suas conseqüências. Motrivivência, Florianópolis, ano XI, n. 12, p. 37-64, maio 1999. Disponível em: <http://www.ludopedio.com.br/rc/upload/ files/180555_13215.pdf $>$. Acesso em: 15 jul. 2013.

REIS, Raul César dos. Entrevista concedida a Heron Heloy Costa em 11 de julho de 2013.

RODRIGO, Sérgio. Entrevista concedida a Heron Heloy Costa em 10 de julho de 2013.

TRIBUNA DO NORTE. Edições 2.931 a 6.569. (Dezembro de 2000 a Dezembro de 2012). 